\title{
Research on the Application of Intangible Cultural Heritage in Visual Communication Design Teaching
}

\author{
1. Zhang Yang yang, 2. Su Zhuan \\ 1.Department Of Art and Design, GuangDong University Of Science \&Technology. \\ Faculty Of Innovation And Design,City University Of Macau. \\ 2. Department Of Art and Design, GuangDong University Of Science \&Technology. \\ Nancheng District, Dongguan, Guangdong
}

\begin{abstract}
Intangible cultural heritage is created in the production and living practice of the Chinese people of all ethnic groups, and is the crystallization of the wisdom and civilization of the Chinese nation. The limited influence of the spread of intangible cultural heritage, the lack of means of transmission and the single form of communication have prevented it from being effectively and widely disseminated and carried forward. The new media has the advantages of objective reality, hypertext, massive information, instant interaction and entertainment, and is welcomed and praised by the public. Therefore, this paper proposes to introduce new media communication into the dissemination of intangible cultural heritage and puts forward corresponding strategies.
\end{abstract}

Keywords-Intangible cultural heritage; Visual communication design; Teaching method

\section{INTRODUCTION}

Intangible cultural heritage is a collection of traditional cultural expressions that have been passed down from generation to generation and regarded as part of cultural heritage, as well as objects and places related to traditional cultural expressions. Intangible cultural heritage is not only a witness to historical development, but also a precious cultural resource of great value. It has an important influence on the character and habits of people of all nationalities in China. China is an ancient country with ancient civilizations. It has a cultural history of more than 5,000 years and has spawned countless outstanding Chinese children. In today's globalized and diversified society, culture is still an important asset of our country and a symbol of China's soft power. As an important part of Chinese culture, intangible cultural heritage, how to carry it forward and inherit and spread is an important topic that cultural workers are constantly thinking about. The following paper explores the dissemination of intangible cultural heritage and the advantages of new media, and explores new media communication strategies for intangible cultural heritage. With the development of China's intangible cultural heritage application, the inclusion of intangible cultural heritage in the education system is the strongest appeal from experts and scholars from all walks of life. Many colleges and universities have begun to try to introduce intangible cultural heritage into the teaching of design art, and to open up the practice of teaching and application of conventional intangible cultural heritage. Especially in recent years, the more the nation is, the more the world is, the more the slogan sounds. The visual communication teaching begins to explore the connotation and design principles of intangible cultural heritage and use it to promote the self-design of students. Modern harmony and unity showcases different artistic charms and attracts the public. It can be said that intangible cultural heritage has a strong practical significance and value in the teaching of visual communication in colleges and universities. Here, the author combines teaching practice and roughly talks about the application of local intangible cultural heritage in the visual communication teaching of local colleges and universities.

\section{OVERVIEW OF THE DISSEMINATION OF INTANGIBLE CULTURAL HERITAGE}

The main means of transmission of China's intangible cultural heritage is traditional media, while traditional media adopts a single mode of dissemination and cannot disseminate intangible cultural heritage in a timely and effective manner. Due to its own characteristics, intangible cultural heritage has obvious regional characteristics, and the way of inheritance is mainly the form of mouth-to-mouth, which leads to its limited scope of communication. For example, the language of ethnic minorities is a gem in Chinese linguistics. However, due to geographical restrictions and the generalization of domestic and international exchanges, dialects or local languages in many languages are lost or assimilated by Chinese, which leads to the language of ethnic minorities. The communication was interrupted.

The spread of traditional intangible cultural heritage mainly includes two ways, one is dynamic face-to-face communication This kind of transmission needs face-to-face, mouth-to-mouth, and there are many intangible cultural heritages that rely on this kind of communication, such as the Northeast Drum, the Hezhe Imakan, the Oroqen Mosu Kun, etc. Time and character restrictions. The other is static display communication, including physical display and photo display. The physical display and photo display, such as the display of handicrafts, can let the audience feel the profoundness of the intangible cultural heritage, and also let the audience appreciate the wisdom of the working people in our country. However, this kind of physical display means has limited objects and limited audience. Carry out detailed learning and dissemination. 
The transmission of intangible cultural heritage is mainly traditional media. The traditional forms of media dissemination are mainly oral communication and physical movement. This form of communication is singular, limited by time, place, person, etc., and therefore cannot be carried out and transmitted more widely. The single form of communication is also not conducive to the enthusiasm of the audience. Many intangible cultural heritages must be felt in a specific area, which limits its spread. Many intangible cultural heritage areas, due to the single form of intangible cultural heritage, and local young people are willing to go to large cities, resulting in many intangible cultural heritage successors.

\section{APPLICATION OF THE CONCEPTION OF ARTISTIC INTENTION IN THE INTANGIBLE CULTURAL HERITAGE}

From the professional point of view, visual communication teaching is the predecessor of art design, which combines certain theoretical knowledge and professional knowledge. Furthermore, the most basic content of visual communication teaching is the design of the work. Design as an art category, it has the function of information transmission. In this way, visual communication teaching needs to penetrate certain skills of conceptual expression of artistic intentions. The nonmaterial cultural heritage incorporates a variety of intentional expressions, such as: traditional Chinese gossip, yin and yang principle ideas, imagery of paper-cutting, three-dimensional imagery of sculpture, and so on. In this regard, the author uses the intentional concept of intangible cultural heritage in teaching to encourage students to find and locate the shape and connotation of self-design. For example, when learning the teaching content of "planar composition", the purpose of the teaching content is to enable students to use the basic elements, lines and faces of the design to arrange and combine the aesthetics. In this part, not only students need to integrate them, but also the works designed and combined by themselves can give people a visual beauty and can convey certain connotations or other information. In the teaching, the author applies the local intangible cultural heritage such as papercutting, shadow-shadowing, clay sculpture, etc., which are of interest to students, that is, taking these as examples to guide students to perceive the contrast between yin and yang in the paper-cutting, the structure and characteristics of the characters in the shadow-shadow. As well as the modeling features in clay sculptures, students are encouraged to have a preliminary understanding and understanding of "planar imagery", and then combine the self-willingness and imagination to determine the plane shape and try the organic integration of points, lines and surfaces.

The key to visual communication teaching is to guide students to transmit certain information through certain elements, which involves the display of visual language. The general students view things and analyze things in the normalization of life, but the visual communication art is different. Students need to think in a way of thinking about things, that is, students need to use art design. Showcases popular information. Students have a lack of understanding of this aspect and can't find a breakthrough point. China's intangible cultural heritage is rich and diverse, such as traditional art, calligraphy, music, dance, drama, art and acrobatics, and each region has With its own unique cultural manifestation form and method, taking embroidery as an example, China has appeared Su embroidery, Yue embroidery, Qian embroidery, Xiang embroidery, Qian embroidery, Gu embroidery, Jing embroidery, Qian embroidery, Lu embroidery, embroidery, embroidery, Han Embroidery, hemp embroidery and Miao embroidery. These contents can be said to be lacking by students. Teachers should reasonably guide students to learn and learn from them. In the teaching, the author uses the expression form of art form elements in the intangible cultural heritage to strengthen the mastery and application of visual language display.

\section{A. Application of color in intangible cultural heritage}

Color is an important part of visual communication teaching. From a visual point of view, when the public appreciates something, its first focus is on the color, and then the color is carefully appreciated and tasted. It can be said that color is the most content that can give people a visual impact. It is not difficult to see in the art series of intangible cultural heritage that different colors represent different meanings, such as: white meaning pure and calm; black meaning calm; purple meaning noble; red meaning festive; Today, people appreciate and choose some things to follow the meaning and meaning of color. In turn, it is decided that students must master the connotation and meaning of the series of colors in the study of visual communication. In this regard, the author believes that teachers use the use of color in the intangible cultural heritage as a case to guide students to analyze, to promote students to understand the role of color in design, and to flexibly use color to express style. For example, in the "color" teaching, the author applies the "Chinese Red" auspicious culture in the intangible cultural heritage to guide students to focus on learning auspicious colors. Namely: First, show the series of intangible cultural heritage of China Red: Facebook, wooden board, paper cutting, etc. Taking the "Fu" of the new year as an example, looking at the various forms of "Fu" paintings, we can easily see that some auspicious and wealthy designs are mainly red in the choice of color, supplemented by gold and yellow. The colors are all expressed in "red", with gold and yellow to guide students to discuss why red is called Chinese red? Such as: such a sense of design, giving people a visual sense of a festive culture, etc., prompting students to perceive the Chinese red to give people visual requirements and satisfaction, experience the auspicious, eager, festive meaning. In this way, with the specific intangible cultural heritage as a case, it is easier for students to understand and apply the colors in traditional culture.

\section{B. Application of design concepts in intangible cultural heritage}

Innovation is the core of the continued development of the art design field. The traditional visual communication teaching is more about letting students memorize some design concepts, such as: natural color, harmonious design. The design of the students has established certain principles, which make the design concept of the students have certain limitations. The real design should not be limited. The design concept in the new era is more people-oriented, and diversified and multi-level design according to people's wishes and needs. That is, the design 
concept must be people-oriented and customer-oriented. Age, occupation, hobbies, cultural level and other characteristics, according to the personal preferences of the client's subjective aspects, "different from person to person." The unique symbolic means and rich styling means in the intangible cultural heritage can open the students' creative thinking. The author uses this as a benchmark to guide students to feel the "newness" in the design concept and strengthen the innovation of the student design concept. Multiple needs, and so on. For example, in the basic graphic teaching, the author displays a variety of pattern patterns, allowing students to observe and learn to create, and to decompose the design in the process of practice to feel the design concept of "change to new" in the plane composition, namely: The plane consists of three basic elements: point, line and surface. Through certain bone transformation and contrast transformation, the expressions of specificity, repetition, space, rhythm and rhythm are used to create the conforming figure. At the same time, students are encouraged to practice their creations. For example, taking an element in the pattern as an example, increasing or decreasing the number of its elements, or changing the size and arrangement of its shape, etc., the graphics displayed will be Another look. Guide students to perceive, feel and appreciate design concepts, strengthen students' ability to try to innovate, break traditional design imprisonment, and integrate a variety of intangible cultural heritage design concepts to present new design styles, such as: dance dynamics, the static of paper cutting, the texture and structure of graphics, and so on. We will continue to inherit the intangible cultural heritage and innovate culture, and deepen the learning and application of visual communication.

\section{INFORMATION VISUALIZATION DESIGN FROM THE PERSPECTIVE OF INTANGIBLE CUltural HERITAGE PROTECTION}

Information visualization design is a branch of information design discipline. Information visualization design includes visual visualization of information graphic design, knowledge, science, data, and development and progress in visual visualization design. Forms, maps, graphics, illustrations, etc. are all forms of information. Whether dynamic or static, we can understand what we want to know, discover various relationships, and achieve the ultimate goal of solving problems. The core part of information visualization design is to present complex information or information itself in an easyto-understand and attractive form of expression.

Another principle of information visualization design is that the expression of information content can be accurate. Therefore, in the specific visual design of the intangible cultural heritage of northern Fujian, we must first clearly define what we want to convey, and we want the reader to How to understand it. For example, in the visual design of the intangible cultural heritage of Yubei Paper-cutting, we have to spend more time and energy on the production materials and production of paper-cutting itself in addition to the simple textual historical statement in visual design. The expression of the method and the production process makes the Xiangyang paper-cutting in the eyes of the reader in a simple and interesting graphical form. Then such a process requires the designers to understand and familiarize with the cultural characteristics and related production techniques of the papercutting of the sun-cut paper, and then spend the time and energy to ensure the authenticity of the intangible cultural heritage. Innovation and development.

Information visual design is one of the visual communication design. It is a visual language that is concise, intuitive and clear. By combing the content itself, through reconstructing the content symbols, visualizing the logical content to the information content itself. Anatomical visual communication. Graphic design expression plays an important role in information visualization design. Information visualization design has the functions of easy identification, emphasis, creativity, accuracy and efficiency. At the same time, there is a certain restrictiveness for the expression of words. The illiterate people cannot understand the description of the words. What is more important is that for foreign audiences, many content can be foreign after having the information visualization design method. It is understood by people that the use of information visualization design methods in the intangible cultural heritage of northern Fujian can expand its own audience, thus promoting the intangible cultural heritage of northern Fujian.

\section{THE ROLE OF INFORMATION VISUALIZATION DESIGN IN THE DEVELOPMENT OF INHERITANCE OF NON-MATERIAL CULTURE}

For the general meaning of the intangible cultural heritage of northern Fujian, its inheritance, communication and development have its own limitations. For example, the way of communication is generally the cultural festival activity or the official behavior of the government, and the comparison of private free market behavior Weak and industrialized. This has led to the general public's lack of access to the material and cultural heritage of northern Fujian, and the intangible cultural heritage is relatively low for the masses. In addition to the sparse access and low free market behavior, the content of the intangible cultural heritage itself in the northern part of the country is too monotonous. For example, when using the new media, most of them are simple and straightforward photo shoots and images. Record, these undesigned original information itself can truly represent the face of the material cultural heritage of northern Fujian, but in the context of today's big information age, it is often difficult to stand out from the crowd in the information age. The information is both complicated and complicated. People are more willing to spend time on interesting things. Therefore, the intangible cultural heritage of northern Fujian is involved in the new media, and it also increases the interest and legibility of the intangible cultural heritage of northern Fujian. Only by satisfying these two conditions at the same time, the essence of non-material culture in northern Fujian can be known by more people, and thus the inheritance and development of non-material culture in northern Fujian can be realized.

For the visual redesign of the intangible cultural heritage in northern Fujian, visual redesign of the specific items of intangible culture in the northern part of the country can be carried out. For example, Xiangyang paper-cutting has a very strong cultural heritage. However, in the course of historical 
development, due to changes in industrial structure, pure papercut artists can no longer rely on paper-cutting to maintain their livelihood, so paper-cutting is the material culture of northern Fujian. The legacy is now in jeopardy, and the people's impression of the paper-cutting process is becoming increasingly blurred. Therefore, in the context of the new media environment, we must make good use of the new media terminal to popularize and spread the culture, crafts and so on of the paper-cutting of the people. Therefore, we must first electronically process all aspects of the paper-cutting of Xiangyang. The application of information visualization design methods. First of all, we can use the two-dimensional highdefinition scanning of the original classic Xiangyang paper-cut to obtain the electronic version of the file, and then use the computer software such as ps or ai visual design software to carry out graphic information redesign, get static graphics or have dynamic effects. Gif graphics. Then these electronic graphics that have been visually designed and visualized are then classified as content. These designed material contents can be put into a special publicity website to spread the information to the official website through the official website. People can also put them into a cultural public welfare app, so that people can understand the paper-cutting of the sun through the mobile app, and this understanding is a comprehensive historical and cultural understanding and The understanding of their own craftsmanship can be fully demonstrated here.

The interactivity of the visual system mainly refers to the visualization of virtual static or dynamic graphics and the interaction between people after the design of the information visualization design method. A more representative case is the "Maoliu" app, which is the main structural form of ancient Chinese architecture and ancient furniture and is one of the important intangible cultural heritages of China. The app's designers also use the information visualization design method to use computer technology and 3D models to visually visualize the reality of the Maoliu structure. When users use this app, they can choose the corresponding Maoliu method to click in, use the touch of the finger and the screen to observe the structure of the front, back, left and right, and also convey the traditional craft culture to the majority of users. So that users can learn and master relevant knowledge in the process of playing. This way has a great positive significance for China's vast handicraft tradition. This method has a strong reference for the intangible cultural heritage of northern Fujian. For the paper-cutting and the first-color pottery of the city, you can use the information visualization design method to use the computer to carry out two-dimensional static graphic dynamic graphics and three-dimensional modeling. The way of indiscriminately spreading the culture of the North African non-legacy to the audience has an important role in the inheritance and protection of the intangible cultural heritage of northern Fujian.

\section{CONCLUSION}

Intangible cultural heritage is the crystallization of the people's labor wisdom, especially its wireless charm and artistic conception are pursued by modern people. As a kind of art design discipline, visual communication is more about cultivating students' aesthetic ability and design ability. Nonmaterial cultural heritage contains a large amount of visual communication cultural content. Teachers should appropriately use local indigenous intangible cultural heritage in teaching, on the one hand, it is convenient for students to guide and perceive beauty, on the other hand, it also helps students to improve. The practice of design concept encourages students to better grasp the essence of traditional art and art activities, and draws on the traditional Chinese folk art's modeling, form beauty and color principle to create local and national integration works.

\section{ACKNOWLEDGMENT}

Guang Dong University Of Science \&Technology Hospital level project: <Dongguan intangible cultural heritage "thousand corner lamp" skills into the visual communication design professional teaching practice research>.Project number:CQ2016042.

Guang Dong University Of Science \&Technology Hospital level project: <Research on the current situation and trend of visual communication design in Dongguan>. Project number:GKY-2017KYQN-20.

Guang Dong University Of Science \&Technology Hospital level project: <Research on the value and development trend of Dongguan soft decoration design industry>. Project number:GKY-2017KYQN-21.

\section{REFERENCES}

[1] Gu Jiqiang. Research on the Intangible Cultural Heritage Communication in the New Media Environment_- Taking the Teapicking Opera in Southern Anhui as an Example [J]. Journal of Journalism of Information Research, 2016(04): 252-253.

[2] Li Jinming. The New Media Inheritance and Protection of Intangible Cultural Heritage [J]. Caizhi, 2014(28): 277-278.

[3] Song Junhua. Interpretation and Reconstruction of the Concept of Intangible Cultural Heritage [J]. Academic Research, 2006(9): 117-121.

[4] Zhang Chunli, Li Xingming. A Review of the Study of the Concept of Intangible Cultural Heritage [J]. Chinese Culture Forum, 2007(2): 137140.

[5] Zhu Bing. Protection and Legislation of Non-physical Cultural Heritage in China [J]. Cultural Heritage, 2012(2): 1-16.

[6] Zhang Bo, Cheng Wei. Protection of Intangible Cultural Heritage from the Perspective of Cultural Tourism [J]. Human Geography, 2008, 23(1): 74-79. 